\title{
Deep Vein Thrombosis and Pulmonary Embolism following Hemorrhagic Stroke
}

\author{
Sung Ho Lee, Won Joo Jeong, Seok Keun Choi, Byung Duk Kwun \\ Department of Neurosurgery, School of Medicine, Kyung Hee University, Seoul, Korea
}

Received: September 22, 2018

Accepted: September 27, 2018

Published: October 10, 2018

\section{Corresponding Author:}

Sung Ho Lee, M.D., Ph.D.

Department of Neurosurgery,

School of Medicine, Kyung Hee

University, 23 Kyung Hee Dae Ro,

Dongdaemoon-gu, Seoul 02447,

Korea

Tel: $+82-2-958-8385$

Fax: +82-2-958-8380

Email:nslsh@khu.ac.kr;

nooname79@gmail.com

\begin{abstract}
Venous thromboembolism (VTE) after stroke is an infrequent but potentially fatal medical complication. The incidence of VTE was shown to be higher in hemorrhagic stroke than in ischemic stroke by several studies; however, no strategy for VTE screening and prophylaxis has been established. Lower extremity ultrasonography (US) is the diagnostic method of choice, but routine application for stroke patients is still debated. For prevention, graduated compression stockings (GCS) have little effect on VTE, and thigh-high GCS should be selected. Early use of intermittent pneumatic compression (IPC) has strong evidence for preventing VTE and is recommended in several clinical guidelines for managing intracerebral hemorrhage (ICH) and subarachnoid hemorrhage (SAH). Prophylactic heparin products are still debated for preventing VTE despite the risk of rebleeding or hematoma enlargement. To date, administering low-dose, low-molecular-weight heparin (LMWH) seems the best method to prevent VTE with less risk of hemorrhagic complications. However, the optimal product, dose, and timing are unclear.
\end{abstract}

Keywords: Venous thromboembolism; Deep Vein Thrombosis; Pulmonary Embolism; Stroke; Intracerebral hemorrhage

\section{BACKGROUND}

Venous thromboembolism (VTE) including deep vein thrombosis (DVT) and pulmonary embolism (PE) are potentenially fatal medical complications following intracerebral hemorrhage $(\mathrm{ICH})$ and subarachnoid hemorrhage (SAH). The incidence of PE after stroke (including both ischemic and hemorrhagic) is less than 1\%; however, PE causes more than $50 \%$ of early deaths after stroke ${ }^{1)}$. As in ischemic stroke, patients with hemorrhagic stroke are prone to DVT due to immobility, possible hemiplegia, and older age.

Methods to prevent and properly manage VTE after ischemic stroke are relatively well established ${ }^{3,4)}$; however, strategies for hemorrhage stroke are not.

\section{REVIEW}

\section{Incidence and risk factors}

The incidence of VTE after stroke varies from 10-75\% depending on the diagnostic criteria, tools, and study $\operatorname{design}^{3,13,21,24)}$. Many studies have reported a higher incidence of DVT or PE after ICH and SAH than after cerebral infarction or transient ischemic attack ${ }^{39}$. In 2003, Gregory et al. retrospectively reported the incidence of DVT after hemorrhagic $(n=1,926)$ and thromboembolic $(n=15,599)$ stroke as $1.9 \%$ and $0.5 \%$, respectively ${ }^{18)}$. Hemorrhagic stroke and length of hospital stay were independent risk factors for DVT. Skaf et al. reported a VTE incidence of $1.93 \%$ ( $1.37 \%$ of DVT and $0.68 \%$ of PE) in $1,605,000 \mathrm{ICH}$ patients in $2005^{38)}$. In 2014, Stecker et al. 
reported that the VTE incidence was 1.3\% (33 of 2613 stroke patients, $\mathrm{DVT}=25, \mathrm{PE}=3$, both $=5$ ) and was higher in $\mathrm{SAH}$ and ICH than in ischemic patients. Higher National Institutes of Health Stroke Scale (NIHSS) score and heart failure were statistically significant risk factors in their study.

Meanwhile, the incidence of DVT is much higher in studies that used lower extremity ultrasonography (US). Lacut et al. reported a DVT incidence of $15.9 \%$ up to 10 days after ICH development ${ }^{27}$. Yablon et al. reported $16 \%$ DVT up to 120 days ${ }^{43)}$. In a Japanese series, Ogata et al. reported that 21 of 52

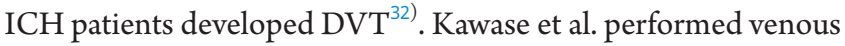
duplex US to detect DVT in $81 \mathrm{ICH}$ patients, and 4, 9, and 17 (21\%) patients were diagnosed at 1,7 , and 14 days, respectively. Female sex was the only independent predictor of DVT.

Although risk factors for stroke-related DVT are still debated, advanced age, high NIHSS score, hemiparesis, immobility, female sex, atrial fibrillation, intravenous or intra-arterial tissue plasminogen activator (tPA), and length of hospital stay have been identified ${ }^{16,28,29)}$. Male sex is considered to be highly associated with DVT in the general population ${ }^{2,12,26,30,31,37)}$.

\section{Diagnosis}

The location and extent of DVT should be identified, because DVT in infra-popliteal calf veins (below-knee or distal DVT) can spontaneously resolve and seldom results in $\mathrm{PE}^{22}$. However, continuous monitoring is crucial because 1 in 6 distal DVTs progresses to proximal DVT, which carries a greater risk of $\mathrm{PE}^{20)}$. Clinical symptoms of DVT appear as local pain or tenderness and local leg edema in approximately $2 / 3$ of DVT patients; however, these symptoms can be hidden in unalert hemorrhagic stroke patients. A clinical DVT prediction score (Wells score) can be useful but is still limited. Thus, it should be combined with D-dimer, (i.e., increased serum C-reactive protein [CRP] with normal fibrinogen with a fever of unknown origin ${ }^{3)}$ ) for evaluation ${ }^{4,42}$.

The most important diagnostic tool is venous duplex US, which is accurate, safe, simple, and portable. Directly watching flow physiology with real-time Doppler imaging (duplex, continuous-wave and color-flow Doppler imaging) provides another advantage ${ }^{20)}$. To detect DVT, US has high sensitivity $(93.2-95.0 \%)$ and specificity $(93.1-94.4 \%)^{17)}$. The limitation of US is that it is only suitable to detect proximal DVT, not distal DVT or DVT above the inguinal canal. In those cases, MR and CT venography of the lower extremity and pelvis with contrast provide high sensitivity and specificity ${ }^{35,41}$.

\section{Prophylaxis \& treatment}

Graduated compression stockings (GCS) / intermittent

\section{pneumatic compression (IPC)}

The CLOTS (Clots in Legs or Stockings After Stroke) trials included three randomized trials assessing the preventive effect of graduated compression stockings (GCS) and intermittent pneumatic compression (IPC) in DVT in stroke patients. In CLOTS 1, 2518 stroke patients (including $232 \mathrm{ICH}$ patients) were enrolled to investigate the preventive effect of thigh-high GCS and did not show reduced DVT, PE, or death ${ }^{8}$. In CLOTS 2, the effectiveness of below-knee GCS and thigh-high GCS were compared in 1406 stroke patients. The incidence of DVT was higher in the below-knee GCS group ( $8.8 \%$ versus $6.3 \%$; absolute difference, $2.5 \%$ points; $95 \%$ confidence interval, [CI] 0.7 to 4.4$)^{9)}$. Finally, CLOTS 3 enrolled 2876 stroke patients (including $376 \mathrm{ICH}$ patients) and found that applying IPC as soon as possible reduced the incidence of DVT. The preventive effect was more prominent in $\mathrm{ICH}$ patients $(6.7 \%$ versus $17.0 \%$; odds ratio [OR], 0.36 ; $95 \% \mathrm{CI} 0.17-0.75)^{10,14)}$. In the 2015 American Heart Association (AHA)/ American Stroke Association (ASA) Guidelines for the Management of Spontaneous $\mathrm{ICH}^{19)}$, GCS is considered not beneficial (Class III, level of evidence [LOE] A), but IPC should be used just after admission (Class I, LOE A). AHA/ASA Guidelines for the Management of Aneurysmal SAH do not describe the use IPC or GCS ${ }^{11)}$, but European Stroke Organization (ESO) Guidelines for the Management of Intracranial Aneurysms and $\mathrm{SAH}^{40)}$ in 2012 and Korean Clinical Practice Guidelines for Aneurysmal $\mathrm{SAH}^{7)}$ in 2018 recommended applying IPC, GCS, or both to prevent DVT.

\section{Unfractionated heparin (UFH) / low-molecular-weight heparin $(L M W H)$}

In ischemic stroke, prophylactic use of heparin or heparinoids has been broadly recommended ${ }^{36)}$. Kamphuisen et al. performed a meta-analysis of 16 randomized controlled trials dealing with heparin use to prevent VTE after acute ischemic stroke. They defined low-dose, unfractionated heparin (UFH) as $\leq 15,000$ $\mathrm{IU} /$ day and low-dose, low-molecular-weight heparin (LMWH) as $\leq 6000 \mathrm{IU} /$ day or weight-adjusted dose $\leq 86 \mathrm{IU} / \mathrm{kg} /$ day. High-dose UFH reduced PE but increased ICH or extracranial hemorrhage (ECH), and low-dose UFH reduced thrombosis but not PE and increased the risk of ICH or ECH. Meanwhile, highdose LMWH decreased both DVT and PE but increased the risk of ICH or ECH, and low-dose LMWH decreased the risk of both DVT (OR=0.34, 95\%; CI $=0.19-0.59)$ and $\mathrm{PE}(\mathrm{OR}=0.36,95 \%$; $\mathrm{CI}=0.15-0.87)$ without increased risk of $\mathrm{ICH}(\mathrm{OR}=1.39,95 \%$ $\mathrm{CI}=0.53-3.67)$ or $\mathrm{ECH}(\mathrm{OR}=1.44,95 \% \mathrm{CI}=0.13-16)$. $\mathrm{ESO}$ guidelines for VTE in immobile patients with acute ischemic stoke recommend prophylactic anticoagulation with UFH 
(5000IU q 12 or 8 hours), LMWH, or a heparinoid ${ }^{15)}$.

Prophylactic use of heparin or heparinoids to prevent DVT after hemorrhagic stroke has not received consensus agreement due to the increased risk of hemorrhage or rebleeding ${ }^{6)}$. In 1991, Boeer et al. administered low-dose UFH (5000 IU per 8 hours) 2 and 10 days after ICH in 68 patients and reported significantly reduced $\mathrm{PE}$ without increasing $\mathrm{ICH}^{5}$. They suggested that heparin can re-open occluded vessels in cerebral infarctions but seldom expands hematomas surrounding cerebral tissue due to elevated pressure. They ultimately recommend its use. Despite several limitations of the study design, several small prospective studies were performed thereafter. Kiphuth et al. reported no fatal PE and a moderate increase in hematoma (20$30 \%$ ) after using LMWH (Enoxafarin 4000IU, dalteparin 2500 IU) within 36 hours for $97 \mathrm{ICH}$ patients ${ }^{25}$. Orken et al. showed that administering $\mathrm{LMWH}$ did not increase ICH but failed to decrease VTE compared to GCS only. In 2011, Paciaroni et al. reported a meta-analysis of four controlled (randomized or nonrandomized) studies of heparin use to prevent DVT in $\mathrm{ICH}$ patients and found that heparin (UFH or LMWH) significantly reduced $\mathrm{PE}$ ( $1.7 \%$ vs. $2.9 \%$; RR, 0.37 ; $95 \% \mathrm{CI}, 0.17-0.80$; $\mathrm{p}=0.01)$ but not DVT (4.2\% vs 3.3\% [RR, 0.77]; 95\%CI, $0.44-1.34 ; \mathrm{p}=0.36)$. However, hemorrhage did not increase significantly (8.0\%vs. 4.0\%; RR, 1.42; 95\% CI, 0.57-3.53; p $=0.45)$ and mortality decreased non-significantly ( $16.1 \%$ vs. 20.9\%; RR, 0.76; 95\% CI, 0.57-1.03; $\mathrm{p}=0.07$ ). They concluded that heparin use should be considered with caution for highrisk patients ${ }^{33)}$. Khan et al. performed a systematic review of DVT in acute stroke and concluded that UFH administration should be considered for high-risk patients even in $\mathrm{ICH}$ and SAH. However, their conclusion does not seem to be clear. AHA/ASA Guidelines for the Management of Aneurysmal $\mathrm{SAH}$ and Korean Clinical Practice Guidelines for Aneurysmal SAH also indicate a lack of sufficient evidence for heparin use in SAH patients ${ }^{7,11)}$. However, the AHA/ASA Guidelines for the Management of Spontaneous ICH recommend low-dose LMWH or UFH for immobile ICH patients 1-4 days from onset until after bleeding stops (Class IIb, LOE B $)^{19)}$. To date, realworld recommendations for low-dose LMWH use are unclear, including optimal timing, dose, and products.

\section{Inferior vena cava (IVC) filter}

Inferior vena cava (IVC) filter insertion is a common method to prevent PE when therapeutic anticoagulation is impossible. However, information comparing IVC filter and anticoagulation is extremely limited ${ }^{23)}$. Moreover, the IVC filter itself can induce thrombosis at the insertion site, perforation of the IVC and adjacent tissue, fracture, or migration. Additionally, IVC filter insertion does not eliminate the need for anticoagulation. Nevertheless, AHA/ASA Guidelines for the Management of Spontaneous ICH recommend IVC filter placement in $\mathrm{ICH}$ patients with symptomatic DVT or PE (Class IIa, LOE C $)^{19)}$.

\section{CONCLUSION}

Because DVT following hemorrhagic stroke is an uncommon but fatal complication, early detection is crucial. Lower extremity US is the most recommended diagnostic tool, but clinical signs are preferred for immobile patients. IPC should be applied just after admission to the intensive care unit to prevent DVT. Although, the evidence is still limited, heparin could be used for high-risk patients; low-dose LMWH seems to be the most preferred form.

$\begin{array}{ll}\text { Abbreviation } \\ \text { ICH } & \text { Intracerebral hemorrhage } \\ \text { SAH } & \text { Subarachnoid hemorrhage } \\ \text { PE } & \text { Pulmonary embolism } \\ \text { DVT } & \text { Deep vein thrombosis } \\ \text { VTE } & \text { Venous thromboembolism } \\ \text { CT } & \text { Computed tomography } \\ \text { MRI } & \text { Magnetic resonance imaging } \\ \text { US } & \text { Ultrasonography } \\ \text { UFH } & \text { Unfractionated heparin } \\ \text { LMWH } & \text { Low-molecular-weight heparin } \\ \text { GCS } & \text { Graduated compression stockings } \\ \text { IPC } & \text { Intermittent pneumatic compression }\end{array}$

\section{CONFLICT OF INTEREST}

No potential conflict of interest relevant to this article was reported.

\section{REFERENCES}

1. The international stroke trial (IST): a randomised trial of aspirin, subcutaneous heparin, both, or neither among 19435 patients with acute ischaemic stroke. International stroke trial collaborative group. Lancet 1997;349:1569- 1581.

2. Anderson FA Jr, Wheeler HB, Goldberg RJ, Hosmer DW, Patwardhan NA, Jovanovic B, et al. A population-based perspective of the hospital incidence and case-fatality rates of deep vein thrombosis and pulmonary embolism. The worcester dvt study. Arch Intern Med 1991;151:933- 938.

3. Bembenek J, Karlinski M, Kobayashi A, Czlonkowska A. Early stroke-related deep venous thrombosis: Risk factors and influence 
on outcome. J Thromb Thrombolysis 2011;32:96-102.

4. Beyer J, Schellong S. Deep vein thrombosis: Current diagnostic strategy. Eur J Intern Med 2005;16:238-246.

5. Boeer A, Voth E, Henze T, Prange HW. Early heparin therapy in patients with spontaneous intracerebral haemorrhage. J Neurol Neurosurg Psychiatry 1991;54:466-467.

6. Chang SH, Shin HS, Lee SH, Koh HC, Koh JS. Rebleeding of ruptured intracranial aneurysms in the immediate postoperative period after coil embolization. J Cerebrovasc Endovasc Neurosurg 2015;17:209-216.

7. Cho WS, Kim JE, Park SQ Ko JK, Kim DW, Park JC, et al. Korean clinical practice guidelines for aneurysmal subarachnoid hemorrhage. J Korean Neurosurg Soc 2018;61:127-166.

8. Collaboration CT, Dennis M, Sandercock PA, Reid J, Graham C, Murray G, et al. Effectiveness of thigh-length graduated compression stockings to reduce the risk of deep vein thrombosis after stroke (clots trial 1): A multicentre, randomised controlled trial. Lancet 2009;373:1958-1965.

9. Collaboration CT. Thigh-length versus below-knee stockings for deep venous thrombosis prophylaxis after stroke: A randomized trial. Ann Intern Med 2010;153:553-562.

10. Collaboration CT, Dennis M, Sandercock P, Reid J, Graham C, Forbes J, et al. Effectiveness of intermittent pneumatic compression in reduction of risk of deep vein thrombosis in patients who have had a stroke (clots 3): A multicentre randomised controlled trial. Lancet 2013;382:516-524.

11. Connolly ES, Rabinstein AA, Carhuapoma JR, Derdeyn CP, Dion J, Higashida RT, et al. Guidelines for the management of aneurysmal subarachnoid hemorrhage: A guideline for healthcare professionals from the american heart association/ american stroke association. Stroke 2012;43:1711-1737.

12. Cushman M, Tsai AW, White RH, Heckbert SR, Rosamond WD, Enright P, et al. Deep vein thrombosis and pulmonary embolism in two cohorts: The longitudinal investigation of thromboembolism etiology. Am J Med 2004;117:19-25.

13. Davenport RJ, Dennis MS, Wellwood I, Warlow CP. Complications after acute stroke. Stroke 1996;27:415- 420.

14. Dennis M, Sandercock P, Murray G, Forbes J, Collaboration CT. Does intermittent pneumatic compression reduce the risk of post stroke deep vein thrombosis? The clots 3 trial: Statistical analysis plan. Trials 2013; 14:66.

15. Dennis M, Caso V, Kappelle LJ, Pavlovic A, Sandercock P. European stroke organisation (eso) guidelines for prophylaxis for venous thromboembolism in immobile patients with acute ischaemic stroke. European Stroke Journal 2016;1:6-19.

16. Douds GL, Hellkamp AS, Olson DM, Fonarow GC, Smith EE, Schwamm LH, et al. Venous thromboembolism in the get with the guidelines-stroke acute ischemic stroke population:
Incidence and patterns of prophylaxis. J Stroke Cerebrovasc Dis 2014;23:123-129.

17. Goodacre S, Sampson F, Stevenson M, Wailoo A, Sutton A, Thomas S, et al. Measurement of the clinical and costeffectiveness of non-invasive diagnostic testing strategies for deep vein thrombosis. Health Technol Assess 2006;10:1-168; iii-iv.

18. Gregory PC, Kuhlemeier KV. Prevalence of venous thromboembolism in acute hemorrhagic and thromboembolic stroke. Am J Phys Med Rehabil 2003;82:364-369.

19. Hemphill JC 3rd, Greenberg SM, Anderson CS, Becker K, Bendok BR, Cushman M, et al. Guidelines for the management of spontaneous intracerebral hemorrhage: A guideline for healthcare professionals from the american heart association/ american stroke association. Stroke 2015;46:2032-2060.

20. Ho VB, van Geertruyden PH, Yucel EK, Rybicki FJ, Baum RA, Desjardins B, et al. Acr appropriateness criteria $\left({ }^{\circledR}\right)$ on suspected lower extremity deep vein thrombosis. J Am Coll Radiol 2011;8:383-387.

21. Kamran SI, Downey D, Ruff RL. Pneumatic sequential compression reduces the risk of deep vein thrombosis in stroke patients. Neurology 1998;50:1683-1688.

22. Kearon C. Natural history of venous thromboembolism. Circulation 2003;107(23 Suppl 1):I22-30.

23. Kelly J, Hunt BJ, Lewis RR, Rudd A. Anticoagulation or inferior vena cava filter placement for patients with primary intracerebral hemorrhage developing venous thromboembolism? Stroke 2003;34:2999-3005.

24. Kelly J, Rudd A, Lewis RR, Coshall C, Moody A, Hunt BJ. Venous thromboembolism after acute ischemic stroke: A prospective study using magnetic resonance direct thrombus imaging. Stroke 2004;35:2320-2325.

25. Kiphuth IC, Staykov D, Kohrmann M, Struffert T, Richter G, Bardutzky J, et al. Early administration of low molecular weight heparin after spontaneous intracerebral hemorrhage. A safety analysis. Cerebrovasc Dis 2009;27:146-150.

26. Kyrle PA, Minar E, Bialonczyk C, Hirschl M, Weltermann A, Eichinger S. The risk of recurrent venous thromboembolism in men and women. N Engl J Med 2004;350:2558-2563.

27. Lacut K, Bressollette L, Le Gal G, Etienne E, De Tinteniac A, Renault A, et al. Prevention of venous thrombosis in patients with acute intracerebral hemorrhage. Neurology 2005;65:865869.

28. Li Z, Liu L, Wang Y, Zhao X, Wang DZ, Wang C, et al. Factors impact the adherence rate of prophylaxis for deep venous thrombosis in acute ischaemic stroke patients: An analysis of the china national stroke registry. Neurol Res 2015;37:427-433.

29. Liu LP, Zheng HG, Wang DZ, Wang YL, Hussain M, Sun HX, et al. Risk assessment of deep-vein thrombosis after acute stroke: 
A prospective study using clinical factors. CNS Neurosci Ther 2014;20:403-410.

30. McRae S, Tran H, Schulman S, Ginsberg J, Kearon C. Effect of patient's sex on risk of recurrent venous thromboembolism: A meta-analysis. Lancet 2006;368:371-378.

31. Moores L, Bilello KL, Murin S. Sex and gender issues and venous thromboembolism. Clin Chest Med 2004;25:281- 297.

32. Ogata T, Yasaka M, Wakugawa Y, Inoue T, Ibayashi S, Okada Y. Deep venous thrombosis after acute intracerebral hemorrhage. J Neurol Sci 2008;272:83-86.

33. Paciaroni M, Agnelli G, Venti M, Alberti A, Acciarresi M, Caso V. Efficacy and safety of anticoagulants in the prevention of venous thromboembolism in patients with acute cerebral hemorrhage: A meta-analysis of controlled studies. J Thromb Haemost 2011;9:893-898.

34. Powers WJ, Rabinstein AA, Ackerson T, Adeoye OM, Bambakidis NC, Becker K, et al. 2018 guidelines for the early management of patients with acute ischemic stroke: A guideline for healthcare professionals from the american heart association/american stroke association. Stroke 2018;49:e46-e110.

35. Sampson FC, Goodacre SW, Thomas SM, van Beek EJ. The accuracy of mri in diagnosis of suspected deep vein thrombosis: Systematic review and meta-analysis. Eur Radiol 2007;17:175181.

36. Sherman DG, Albers GW, Bladin C, Fieschi C, Gabbai AA, Kase CS, et al. The efficacy and safety of enoxaparin versus unfractionated heparin for the prevention of venous thromboembolism after acute ischaemic stroke (prevail study): An open-label randomised

37. Silverstein MD, Heit JA, Mohr DN, Petterson TM, O'Fallon WM, Melton LJ. Trends in the incidence of deep vein thrombosis and pulmonary embolism: A 25-year populationbased study. Arch Intern Med 1998;158:585- 593.

38. Skaf E, Stein PD, Beemath A, Sanchez J, Bustamante MA, Olson RE. Venous thromboembolism in patients with ischemic and hemorrhagic stroke. Am J Cardiol 2005;96:1731-1733.

39. Stecker M, Michel K, Antaky K, Cherian S, Koyfmann F. Risk factors for dvt/pe in patients with stroke and intracranial hemorrhage. Open Neurol J 2014;8:1-6.

40. Steiner T, Juvela S, Unterberg A, Jung C, Forsting M, Rinkel G, et al. European stroke organization guidelines for the management of intracranial aneurysms and subarachnoid haemorrhage. Cerebrovasc Dis 2013;35:93-112.

41. Thomas SM, Goodacre SW, Sampson FC, van Beek EJ. Diagnostic value of ct for deep vein thrombosis: Results of a systematic review and meta-analysis. Clin Radiol 2008;63:299-304.

42. Wells PS, Owen C, Doucette S, Fergusson D, Tran H. Does this patient have deep vein thrombosis? JAMA 2006;295:199-207.

43. Yablon SA, Rock WA, Nick TG, Sherer M, McGrath CM, Goodson KH. Deep vein thrombosis: Prevalence and risk factors in rehabilitation admissions with brain injury. Neurology 2004;63:485-491. 